\title{
A Prospective Randomized Clinical Study on Spinal Anaesthesia Using Isobaric Levobupivacaine Versus Hyperbaric Bupivacaine (with Fentanyl) in Elective Caesarean Sections
}

\author{
S. Kalyan¹, Ch. Anil Kumar² \\ 1, 2 Department of Anaesthesiology, Viswabharathi Medical College and Hospital, \\ Penchikalapadu, Kurnool, Andhra Pradesh, India.
}

\section{ABSTRACT}

\section{BACKGROUND}

Bupivacaine being an amide is used in hyperbaric and isobaric forms as a spinal anaesthetic for surgeries requiring regional anaesthesia. Spinal anaesthesia is an accepted form of anaesthesia for elective and emergency caesarean sections. Bupivacaine used in spinal anaesthesia produces analgesia, anaesthesia, and motor block. Grading the effects of the anaesthetic is based on volume, concentration, and dose. The present study analysed the role of both types of bupivacaine supplemented by fentanyl. Here we wanted to study the anaesthetic effects of isobaric levobupivacaine versus hyperbaric bupivacaine where both were supplemented by fentanyl while being used as a spinal anaesthetic in patients operated for caesarean section.

\section{METHODS}

A prospective double-blind study was conducted on 104 women undergoing caesarean sections under spinal anaesthesia at Viswabharathi Medical College, RT Nagar, Penchikalapadu, Kurnool. Women with gestational age of above 37 weeks were included. Patients were classified into Group A: levobupivacaine $10 \mathrm{mg} 0.5 \%$ in $2 \mathrm{ml}$ with fentanyl $25 \mu \mathrm{g}$ in $0.5 \mathrm{ml}$ used intrathecally; Group B: Hyperbaric bupivacaine $10 \mathrm{mg} 0.5 \%$ in $2 \mathrm{ml}$ with fentanyl $25 \mu \mathrm{g}$ in $0.5 \mathrm{ml}$ used intrathecally. The time for maximum sensory block, time regression of sensory block to two dermatomes, the time taken to $r$ for regression from maximum to T12 were recorded. A Bromage scale (modified) helped to assess the motor block. Time taken for onset of motor block, the time taken to reach Bromage 3 and the time of complete disappearance were recorded.

\section{RESULTS}

The onset of sensory block was late in group A compared to group B. The time taken to reach the T10 sensory block was shorter in group B compared to group A, the time taken to reach T4 was longer in group A and shorter in group B. The time for regression of two dermatomes was longer in group B when compared to group A. The total duration of sensory blockade was longer in group $B$ than in group $A$. The time of onset of motor block in Group B was shorter than in Group A.

\section{CONCLUSIONS}

Both levobupivacaine and hyperbaric bupivacaine provided quick and desirable induction of surgical anaesthesia for caesarean operations in full-term pregnant women. They did not cause adverse effects on hemodynamic homeostasis and the neonates.

\section{KEY WORDS}

Spinal Anaesthesia, Local Anaesthetic, Fentanyl, Bupivacaine, Motor Block, Sensory Block.
Corresponding Author: Dr. Ch. Anil Kumar, Department of Anaesthesiology, Viswabharathi Medical College and Hospital, Penchikalapadu, Kurnool, Andhra Pradesh, India.

E-mail: thalithakumidhanya@gmail.com

DOI: $10.14260 /$ jemds $/ 2022 / 22$

How to Cite This Article:

Kalyan S, Kumar CA. A prospective randomized clinical study on spinal anaesthesia using isobaric levobupivacaine versus hyperbaric bupivacaine (with fentanyl) in elective caesarean sections. J Evolution Med Dent Sci 2022;11(01):115119, DOI: $10.14260 /$ jemds/2022/22

Submission 22-12-2021,

Peer Review 29-12-2021,

Acceptance 23-01-2022,

Published 28-01-2022.

Copyright (C) 2022 S. Kalyan et al. This is an open access article distributed under Creative Commons Attribution License [Attribution 4.0 International (CC BY 4.0)] 


\section{BACKGROUND}

Intrathecal administration of bupivacaine is commonly used for women undergoing caesarean operations all over the world. It is preferred by many surgeons and anaesthetists for caesarean sections because it produces perfect analgesia, sensory block, and motor block. ${ }^{1}$ But the outcome of spinal anaesthesia depends upon the volume, concentration, and doses of the anaesthetic drug used.2,3 The commonly used spinal anaesthetic is $0.5 \%$ hyperbaric bupivacaine. Even though it is remarkable in its safety, sensory block and motor blockade effects, it is not free of risks.,5 Hyperbaric anaesthetic agents are known to cause cardiac arrests due to sympathetic extension. Hypotension or bradycardia after mobilization or extension or early return of the block may be seen. ${ }^{6}$ But the isobaric anaesthetic agents are less sensitive to positional changes in patients. ${ }^{7}$ Currently the use of levorotatory bupivacaine has come in for spinal anaesthesia and is known to have lesser side effects such as cardiac arrest and neurotoxicity. ${ }^{8}$ The normal levobupivacaine was also shown as isobaric with CSF of pregnant women. ${ }^{9}$ Supplementing opioids during spinal anaesthesia with bupivacaine, reduces the side effects related to the local anaesthetic used and also produces good quality intra and postoperative analgesia by minimizing the total dose of spinal anaesthetic. ${ }^{10}$ Fentanyl, a lipophilic opioid, when used along with local anaesthetics for spinal anaesthesia, results in prolonged duration of action of the local anaesthetic and improves the sensory block. ${ }^{11}$ Combination of fentanyl and local anaesthetic bupivacaine intrathecally has been used in all types of general surgeries, caesarean sections and orthopaedic operations. ${ }^{12,13}$ The doses of fentanyl range from 2.5 to $50 \mu \mathrm{g}$ in the spinal block for a caesarean section, but the most commonly used dosage is $25 \mu \mathrm{g} .{ }^{14}$ On the other hand, certain studies have shown that intrathecal fentanyl is associated with increased demand for opioid analgesics in the postoperative period, which may be due to faster onset of tolerance to opioids and /or opioid-induced hyperalgesia. These studies also reported a ceiling effect of fentanyl above $0.25 \mu \mathrm{g} . \mathrm{kg}-1$, concluding that higher doses of fentanyl do not improve the quality of analgesia but it increase adverse effects. The present study was intended to analyse the effective role of hyperbaric bupivacaine in comparison to isobaric bupivacaine supplemented by fentanyl in both, for spinal anaesthesia in patients operated for caesarean section.

\section{METHODS}

It is a prospective randomized sectional double-blind study conducted in Viswabharathi Medical College, RT. Nagar, Penchikalapadu, Kurnool, Andhra Pradesh from January 2017 to December 2018. 104 women undergoing caesarean operations were included in this study. An institutional ethical committee approval and committee approved consent form was used.

\section{Inclusion Criteria}

Women with more than 37 weeks gestation were included. Women aged between 23 and 40 years were included,
Women with ASA physical status classes I and II were included.

\section{Exclusion Criteria}

Women aged below 23 years and above 40 years were excluded. Women refusing regional anaesthesia were excluded. Women with contraindications for spinal anaesthesia were excluded. Women with obesity (more than $100 \mathrm{Kgs}$ ), shorter (less than $150 \mathrm{cms}$ ) and taller than $175 \mathrm{cms}$ were excluded. Those who received medications except perinatal calcium, vitamins, proteins and iron supplementation were excluded. Women with systemic diseases were excluded. Women with previous foetal anomalies were excluded. Women with a previous history of abruptio placenta and placenta previa were excluded from the study.

Demographic data of all the subjects such as pulse oximetry, ECG and non-invasive blood pressure were recorded. IV infusion of Ringer lactate solution $15 \mathrm{ml} / \mathrm{kg}$ was administered. Mean of three B.P recordings was taken as baseline BP reading. In the left lateral position, after antiseptic preparation of the midline spine, $2 \%$ lidocaine was infiltrated. Lumbar puncture was done between L3 and L4 spinous processes with a 25 -gauge spinal needle. Among the 104 patients, in 52 group A patients, $10 \mathrm{mg}$ isobaric levobupivacaine in $0.5 \%$ of $2 \mathrm{ml}$ and fentanyl $25 \mu \mathrm{g}$ in $0.5 \mathrm{ml}$ were used. The remaining 52 (Group B) were given $10 \mathrm{mg} 0.5$ $\%(2 \mathrm{ml})$ hyperbaric bupivacaine and $25 \mu \mathrm{g}(0.5 \mathrm{ml})$ fentanyl. In both groups, the intrathecal drug volume was a total of 2.5 cc given within 10 seconds. Soon after intrathecal spinal injection, subjects were placed in the supine position; 4 $\mathrm{L} / \mathrm{min}$ of oxygen was used via a facial mask. Sensory block achievement was identified using needle and cotton swab. The time-lapse between intrathecal local anaesthetic injection and total development of sensory block was checked minute wise initially for 15 minutes, later at every 5 minutes till the end of the surgery. Pulse rate, B.P were recorded every 5 minutes till the end of surgery. The extent of the motor block was also recorded at the same intervals. Surgery was allowed when the block was at the T4-T6 level. After intrathecal injection for spinal anaesthesia, time was noted from 0 minute to 1 . The time lapse for the beginning of the sensory block, 2. Time for maximum sensory block and its level, 3. Time for losing sensory block to minimum two dermatomes, 4 . Time for the regression of the sensory block to T12 from the maximum level were recorded. Modified Bromage scale 3 (no paralysis, ability to flex hips/knees/ankles=0; able to move knees, unable to raise extended legs $=1$; able to flex ankles, unable to flex knees $=2$; unable to move any part of the lower limb = 3), 15 to assess the motor block was used. Time scales used were: 1 . The onset of motor block, 2. Time taken to reach Bromage 3 and 3 . Complete disappearance of motor block was noted down. Newborn infants' clinical status was examined using Apgar score and blood gas analysis from cord blood. After shifting the women to the postoperative ward the following parameters were recorded. 1. Vital signs, 2. Blockades of motor and sensory levels, every $30 \mathrm{~min}$ for $3 \mathrm{~h}$ and then on every $4^{\text {th }}$ hourly were noted. Bradycardia was considered with pulse rate $<50$ (treated with $0.6 \mathrm{mg}$ IV atropine). More 
than $30 \%$ fall in systemic B.P was treated as hypotension with boluses of $6 \mathrm{mg}$ ephedrine and additional IV fluids. The total dose of ephedrine used was recorded for each patient. Required analgesic rescue doses were recorded (IV $75 \mathrm{mg}$ diclofenac sodium was used for all patients). Incidences of nausea and vomiting during the surgery and after surgery for 24 hours were noted and recorded (treated with IV ondansetron $4 \mathrm{mg}$ ).

\section{Statistical Analysis}

Standard statistical methods like percentage, $p$-value and mean \pm standard deviation were used.

\section{RESULTS}

The demographic data of the two groups in this study had no significant statistical difference as shown in Table 1. ANOVA one-way analysis of variance was used to calculate the significance.

\begin{tabular}{|cccc|}
\hline Observation & Group A & Group B & P-Value \\
\hline Age in years & $26.13 \pm 4.15$ & $25.60 \pm 3.95$ & \\
Weight in Kg & $62.70 \pm 5.10$ & $60.35 \pm 3.85$ & \\
Height in cms & $158.30 \pm 2.10$ & $160.05 \pm 3.80$ & \\
Gestational age in weeks & $37.5 \pm 0.55$ & $37.80 \pm 0.58$ & \\
Heart rate & $68.20 \pm 4.50$ & $71.20 \pm 3.15$ & \\
Systolic Blood Pressure & $114.60 \pm 4.25$ & $112.50 \pm 3.70$ & 0.997 \\
\hline Table 1. Demographic Data of Both the Group Subjects \\
(N-104; Group A-52, Group B-52) & \\
\hline
\end{tabular}

The onset of sensory block was delayed in group A more than in group B. The lapse for the development of sensory block to reach $\mathrm{T} 10$ was lesser in group B patients than group A patients, the time-lapse to achieve the T4 level was more in group A than in group B patients, the time-lapse to reversal of sensations to two dermatomes was prolonged in Group B patients than in group A patients. The total duration of sensory blockade was higher in group B than in group A patients. The time of onset of motor block in Group B was shorter than in Group A. Total motor blockade (Bromage 3) was noted in $15 \mathrm{~min}$ in all patients in both groups. The total motor blockade duration was higher in group B than in group A patients. Motor blockades developed rapidly and lasted longer with the hyperbaric bupivacaine and fentanyl group (Group B), (Table 2). A T-Test calculator for 2 dependent means was used to calculate the significance between the values of the two treatment regimens for all the variables.

\begin{tabular}{|c|c|c|c|c|}
\hline & Observation & Group A & Group B & P-Value \\
\hline \multirow{4}{*}{ Sensory Block } & Onset of Sensory Block (min) & $2.4 \pm 0.25$ & $1.8 \pm 0.15$ & 0.00001 \\
\hline & Time taken to reach $\mathrm{T} 10(\mathrm{~min})$ & $4.9 \pm 0.35$ & $4.2 \pm 0.50$ & 0.00001 \\
\hline & Time taken to reach $\mathrm{T} 4$ (min) & $5.91 \pm 1.10$ & $4.85 \pm 1.30$ & 0.00001 \\
\hline & Time for reversal of two dermatomes ( $\mathrm{min}$ ) & $77.50 \pm 4.10$ & $85.60 \pm 3.65$ & 0.00001 \\
\hline \multirow{3}{*}{ Motor Block } & Onset of motor blockade (min) & $3.7 \pm 0.62$ & $2.4 \pm 0.31$ & 0.00001 \\
\hline & Time taken to achieve max level (min) (Bromage 3) & $12.10 \pm 3.06$ & $10.01 \pm 1.45$ & 0.00001 \\
\hline & Total duration of motor block (min) & $95.40 \pm 10.05$ & $117.55 \pm 14.85$ & 0.00001 \\
\hline Analgesia & Duration of Analgesia (min) & $160.50 \pm 11.55$ & $174.30 \pm 8.65$ & 0.00001 \\
\hline & le 2. Intraoperative and Postoperative Anat & $s(N-104 ; G r o$ & roup B-52) & \\
\hline
\end{tabular}

Bradycardia and hypotension were noted in a larger number of patients of group B than group A, but it was not significant statistically. Other adverse effects: nausea, vomiting, backache were observed in a large number of patients of group B than group A; not statistically significant (Table 3).

\begin{tabular}{|cccc}
\hline Observation & Group A & Group B & 09 \\
Bradycardia & 05 & 04 & 0.210 \\
Hypotension & 03 & 02 & 03 \\
Backache & 01 & 02 & 0.414 \\
Nausea & 01 & 0 & 0.365 \\
Vomiting & 02 & 0.254 \\
Itching & 01 & 0.120 \\
Sedation & 0 & 0.165 \\
Rigors & 01 & 0.202 \\
\hline & Table 3. The Side Effects Observed in the Study (N-104; Group A-52, Group B-52) \\
\hline
\end{tabular}

Hemodynamic changes observed in the form of systemic systolic and diastolic blood pressures in the study subjects showed more stability in group A than in group B. The fall in mean arterial pressure in patients belonging to group B was more frequent and more substantial than in group A (Table 4). At least 13 patients required administration of IV ephedrine.

\begin{tabular}{|c|c|c|c|c|}
\hline \multirow{2}{*}{ Observation } & \multicolumn{2}{|c|}{ Group A } & \multicolumn{2}{|c|}{ Group B } \\
\hline & SBP & SBP & DBP & DBP \\
\hline Basal values & $126.45 \pm 8.10$ & $124.50 \pm 6.40$ & $82.30 \pm 4.20$ & $80.60 \pm 2.90$ \\
\hline \multicolumn{5}{|l|}{ After Spinal Anaesthesia } \\
\hline $1 \mathrm{~min}$ & $121.20 \pm 3.85$ & $77.24 \pm 1.7$ & $119.30 \pm 2.40$ & $75.23 \pm 1.70$ \\
\hline $2 \min$ & $119.50 \pm 4.10$ & $78.31 \pm 1.5$ & $117.50 \pm 1.60$ & $77.45 \pm 1.65$ \\
\hline $3 \mathrm{~min}$ & $118,50 \pm 4.25$ & $78.28 \pm 2.1$ & $114.63 \pm 3.10$ & $76.65 \pm 1.55$ \\
\hline $4 \mathrm{~min}$ & $115.80 \pm 3.70$ & $79.41 \pm 3.0$ & $112.24 \pm 3.25$ & $75.70 \pm 1.45$ \\
\hline $5 \mathrm{~min}$ & $116.30 \pm 4.15$ & $76.26 \pm 2.2$ & $110.21 \pm 3.76$ & $74.85 \pm 1.36$ \\
\hline $10 \mathrm{~min}$ & $112.20 \pm 6.10$ & $76.23 \pm 2.3$ & $109.30 \pm 3.15$ & $74.82 \pm 1.50$ \\
\hline $15 \mathrm{~min}$ & $113.94 \pm 4.68$ & $75.50 \pm 2.7$ & $107.24 \pm 1.30$ & $74.90 \pm 1.60$ \\
\hline $20 \mathrm{~min}$ & $110.74 \pm 5.89$ & $77.45 \pm 2.8$ & $106.71 \pm 2.30$ & $73.24 \pm 1.44$ \\
\hline $30 \mathrm{~min}$ & $111.83 \pm 7.30$ & $78.81 \pm .2 .9$ & $108.30 \pm 2.25$ & $78.44 \pm 2.47$ \\
\hline $45 \mathrm{~min}$ & $115.94 \pm 5.38$ & $79.90 \pm 1.8$ & $111.16 \pm 2.11$ & $77.46 \pm 3.13$ \\
\hline At the end of surgery & $121.34 \pm 4.90$ & $71.55 \pm 3.26$ & $113.60 \pm 7.80$ & $65.70 \pm 4.20$ \\
\hline
\end{tabular}


As for clinical data in the newborn, there was no significant statistical difference between the two groups in terms of their APGAR scores at $1 \mathrm{~min}$ and $5 \mathrm{~min}$ after delivery and cord blood gas analysis (Table 5). The data was within the physiological range of a normal newborn child.

\begin{tabular}{|cccc|}
\hline & Observation & Group A & Group B \\
APGAR score & $1 \mathrm{~min}$ & $8.93 \pm 0.68$ & $9.04 \pm 1.01$ \\
& $5 \mathrm{~min}$ & $9.12 \pm 0.17$ & $9.56 \pm 1.31$ \\
& $\mathrm{PH}$ & $7.42 \pm 0.04$ & $7.39 \pm 0.05$ \\
Cord blood analysis & $\mathrm{PO} 2$ & $44.20 \pm 6.45$ & $48.18 \pm 7.15$ \\
& $\mathrm{PCO} 2$ & $24.10 \pm 4.10$ & $23.50 \pm 2.00$ \\
& $\mathrm{HCO}$ & $21.6 \pm 1.98$ & $22.30 \pm 1.65$ \\
\hline \multicolumn{3}{|c|}{ Table 5. Apgar Score and Cord Blood Gas Analysis for Oxygen (N-104; } \\
& Group A-52, Group B-52) \\
\hline
\end{tabular}

\section{DISCUSSION}

The addition of fentanyl in this study was based on the doseresponse relationship of fentanyl with other local anaesthetic drugs used all over the world in clinical studies on caesarean operations. Goel et al. ${ }^{16}$ concluded from their study that fentanyl when added to low doses of different local anaesthetic agents would produce a synergistic action of analgesia and sensory block without producing untoward sympathetic blockade or delaying recovery of sensory and motor blocks. The period of analgesia (sensory block) was longer in group B when compared to group A. The time taken for the onset of sensory blockade was shorter in group $B$ patients when compared to group A patients, according to the study by Ayesha Goel ${ }^{17}$ who reported that the onset of sensory blockade was shorter with hyperbaric bupivacaine than levobupivacaine. The level of sensory blockade achieved in this study was T4-T5 and the time taken to reach the highest sensory block was shorter in group B patients than group A patients (Table 2). These results observed in this study were statistically significant $(\mathrm{P}$-value $<0.05)$. But in a study similar to this by P. Gautier et al. ${ }^{18}$ the difference between the two groups was not statistically significant. The motor blockade achieved in this study showed that the time of onset of motor block in Group B was shorter than Group A. Complete motor block was obtained within $15 \mathrm{~min}$ in all patients in both groups (Bromage 3). The total duration of motor blockade was longer in group B than in group A. Motor block developed faster and lasted longer with the hyperbaric bupivacaine and fentanyl group (Group B), (Table 2). Similar findings were reported from the study of Ayesha Goyal et al. (18). Glaser C et al. ${ }^{19}$ who found an insignificant result in regards to the onset of the motor block with bupivacaine and levobupivacaine. In this study, group B patients achieved Bromage 3 score in a shorter time than group A. This result was comparable with studies done by Coppejans et al. ${ }^{20}$ who also reported that the time taken to obtain motor block Bromage 3 was significantly shorter. There was no foetal toxicity reported after birth in the present study in either of the groups. Newborn clinical data were compared among the patients of the two groups and found that there was no significant statistical difference between the two groups in terms of APGAR scores at $1 \mathrm{~min}$ and $5 \mathrm{~min}$ after birth and cord gas analysis (Table 5). The data was within the physiological range of a normal newborn child. It may be due to the slow absorption of anaesthetic agents into the general circulation after injection through the intrathecal route. The absorption rate of bupivacaine and levobupivacaine was said to come down by $1 / 10^{\text {th }}$ of the total dose given. ${ }^{21}$ The hemodynamic changes observed in the form of systemic systolic and diastolic blood pressures in the study subjects showed more stability in group A than in group B. The fall in mean arterial pressure in patients belonging to group B was more frequent and more substantial than in group A (Table 4). 13 patients required administration of IV ephedrine. A review of the literature showed that the effect of local anaesthetics on sensory blockade by their action on the spinal neural elements was enhanced by adding opioids. Their combinations resulted in improved and prolonged anaesthesia and analgesia. The combinations have also produced a more stable status in patients with very low dose requirements. ${ }^{22,23}$ In a similar study by Gulen Guler et al. ${ }^{24}$ $16.6 \%$ of their patients who were given levobupivacaine and $36.6 \%$ of the patients who were given bupivacaine developed hypotension. The results of this study were also similar.

\section{CONCLUSIONS}

Both levobupivacaine and hyperbaric bupivacaine provided quick and desirable induction of surgical anaesthesia for caesarean operations in full-term pregnant women. They did not cause adverse effects on hemodynamic homeostasis and the neonates. The combination with fentanyl produced shorter duration motor blockade with levobupivacaine than with hyperbaric levobupivacaine.

Data sharing statement provided by the authors is available with the full text of this article at jemds.com.

Financial or other competing interests: None.

Disclosure forms provided by the authors are available with the full text of this article at jemds.com.

\section{REFERENCES}

[1] Uppal V, Retter S, Casey M, et al. Efficacy of intrathecal fentanyl for cesarean delivery: a systematic review and meta-analysis of randomized controlled trials with trial sequential analysis. Anesth Analg 2020;130(1):111-25.

[2] Gautier P, De Kock M, Van Steenberge A, et al. A doubleblind comparison of $0.125 \%$ ropivacaine with sufentanil and $0.125 \%$ bupivacaine with sufentanil for epidural labor analgesia. Anesthesiology 1999;90(3):772-8.

[3] Brizzi A, Greco F, Malvasi A, et al. Comparison of sequential combined spinal-epidural anesthesia and spinal anesthesia for cesarean section. Minerva Anestesiol 2005;71(11):701-9.

[4] Hallworth SP, Fernando R, Columb MO, et al. The effect of posture and baricity on the spread of intrathecal bupivacaine for elective cesarean delivery. Anesth Analg 2005;100(4):1159-65.

[5] Køhler F, Sørensen JF, Helbo-Hansen HS. Effect of delayed supine positioning after induction of spinal anaesthesia for caesarean section. Acta Anaesthesiol Scand 2002;46(4):441-6. 
[6] Løvstad RZ, Granhus G, Hetland S. Bradycardia and asystolic cardiac arrest during spinal anaesthesia: a report of five cases. Acta Anaesthesiol Scand 2000;44(1):48-52.

[7] Povey HM, Jacobsen J, Westergaard-Nielsen J. Subarachnoid analgesia with hyperbaric $0.5 \%$ bupivacaine: effect of a 60 -min period of sitting. Acta Anaesthesiol Scand 1989;33(4):295-7.

[8] Huang YF, Pryor ME, Mather LE, et al. Cardiovascular and central nervous system effects of intravenous levobupivacaine and bupivacaine in sheep. Anesth Analg 1998;86:797-804.

[9] McLeod GA. Density of spinal anaesthetic solutions of bupivacaine, levobupivacaine, and ropivacaine with and without dextrose. Br J Anaesth 2004;92(4):547-51.

[10] American Society of Anesthesiologists Task Force on Obstetric Anesthesia. Practice guidelines for obstetric anesthesia: an updated report by the American Society of Anesthesiologists Task Force on Obstetric Anesthesia. Anesthesiology 2007;106(4):843-63.

[11] Ben-David B, Solomon E, Levin H, et al. Intrathecal fentanyl with small-dose dilute bupivacaine: Better anesthesia without prolonging recovery. Anesth Analg 1997;85(3):560-5.

[12] Gupta A, Axelsson K, Thörn SE, M et al. Low-dose bupivacaine plus fentanyl for spinal anesthesia during ambulatory inguinal herniorrhaphy: a comparison between $6 \mathrm{mg}$ and $7.5 \mathrm{mg}$ of bupivacaine. Acta Anaesthesiol Scand 2003;47(1):13-9.

[13] Barkshire K, Russell R, Burry J, et al. A comparison of bupivacaine-fentanyl-morphine with bupivacainefentanyl-diamorphine for caesarean section under spinal anaesthesia. Int J Obstet Anesth 2001;10(1):4-10.

[14] Hunt CO, Naulty JS, Bader AM, et al. Perioperative analgesia with subarachnoid fentanyl bupivacaine for cesarean delivery. Anesthesiology 1989;71(4):535-40.
[15] Bromage PR. Epidural analgesia. Philadelphia: WB Saunders 1978: p. 144.

[16] Goel S, Bhardwaj N, Grover VK. Intrathecal fentanyl added to intrathecal bupivacaine for day case surgery: A randomized study. Eur J Anaesthesiol 2003;20(4):294-7.

[17] Goyal A, Shankaranarayan P, Ganapathi P. A randomized clinical studycomparing spinal anesthesia with isobaric levobupivacaine with fentanyl and hyperbaric bupivacaine with fentanyl in elective cesarean sections. Anesth Essays Res 2015;9(1):57-62.

[18] Gautier P, De Kock M, Huberty L, et al. Comparison of the Effects of intrathecal ropivacaine, levobupivacaine and bupivacaine for caesarean section. $\mathrm{Br} \mathrm{J}$ Anaesth 2003;91(5):684-9.

[19] Glaser C, Marhofer P, Zimpfer G, et al. Levobupivacaine versus racemic bupivacaine for spinal anesthesia. Anesth Analg 2002;94(1):194-8.

[20] Coppejans HC, Vercauteren MP. Low-dose combined spinal-epidural anesthesia for cesarean delivery: a comparison of three plain local anesthetics. Acta Anaesthesiol Belg 2006;57(1):39-43.

[21] Erbay RH, Ermumcu O, Hanci V, et al. A comparison of spinal anesthesia with low-dose hyperbaric levobupivacaine and hyperbaric bupivacaine for transurethral surgery: a randomized controlled trial. Minerva Anestesiol 2010;76(12):992-1001.

[22] Choi DH, Ahn HJ, Kim MH. Bupivacaine-sparing effect of fentanyl in spinal anesthesia for cesarean delivery. Reg Anesth Pain Med 2000;25(3):240-5.

[23] Ben-David B, Miller G, Gavriel R, et al. Low-dose bupivacaine-fentanyl spinal anesthesia for cesarean delivery. Reg Anesth Pain Med 2000;25(3):235-9.

[24] Guler G, Cakir G, Ulgey A, et al. A Comparison of spinal anesthesia with levobupivacaine and hyperbaric bupivacaine for cesarean sections: a randomized trial. Open Journal of Anesthesiology 2012,2(3):84-9. 